\title{
An Alternative Bacterial Expression System Using Bacillus pumilus SG2 Chitinase Promoter
}

\author{
Kambiz Morabbi Heravi 1, Garshasb Rigi ${ }^{2}$, Maryam Rezaei Arjomand ${ }^{3}$, Amin Rostami ${ }^{\text {3, Gholamreza }}$ \\ Ahmadian 3,* \\ ${ }^{1}$ Institut für Industrielle Genetik, Universität Stuttgart, Allmandring 31, 70569 Stuttgart, Germany \\ ${ }^{2}$ Department of Biology, Faculty of Science, Behbahan Khatam Alanbia University of Technology, Behbahan, Iran \\ ${ }^{3}$ Department of Industrial and Environmental Biotechnology, National Institute of Genetic Engineering and Biotechnology \\ (NIGEB), Tehran, Iran
}

* Corresponding author: Gholamreza Ahmadian, Department of Industrial and Environmental Biotechnology, National Institute of Genetic Engineering and Biotechnology (NIGEB), Tehran, Iran. Tel: +98-2144787301-10, Fax: +98-2144787399, E-mail: ahmadian@nigeb.ac.ir

Received: April 27, 2015; Revised: September 20, 2015; Accepted: October 03, 2015

\begin{abstract}
Background: Chitin is an abundant natural polysaccharide found in fungi, algae, and exoskeleton of insects. Several bacterial species are capable of utilizing chitin as their carbon source. These bacteria produce chitinases for degradation of chitin into $N$-acetyl-D-glucosamine. So far, regulation of the chitinase encoding genes has been studied in different bacterial species. Among Bacillus species, B. pumilus strain SG2 encodes two chitinases, ChiS and ChiL. The promoter region of chiSL genes $\left(\mathrm{P}_{c h i S}\right)$ is mainly regulated by the general carbon catabolite repression $(\mathrm{CCR})$ system in $B$. subtilis due to the presence of a catabolite responsive element (cre).

Objectives: Use of $\mathrm{P}_{c h i S}$ in constructing an inducible expression system in B. subtilis was investigated.

Materials and Methods: In the first step, complete and shortened versions of $\mathrm{P}_{\text {chiS }}$ were inserted upstream of the lac $Z$ on a pBS72/pUC18 shuttle plasmid. The $\beta$-galactosidase activity of $B$. subtilis carrying one of the relevant plasmids was measured in the presence of different carbon sources.

Results: An expression system based on the chitinase promoter of $B$. pumilus $\mathrm{SG} 2$ was established. Modification of $\mathrm{P}_{\text {chiS }}$ and the culture medium resulted in production of $\beta$-galactosidase in B. subtilis up to 1,800 Miller unit (MU) activity.

Conclusions: The chitinase promoter developed in this study, has potential to be used in an expression vector that could be induced by chitin. In addition, compared to the other inducers like IPTG and lactose, chitin is definitely cheaper and more available as an inducer.

Keywords: Carbon catabolite repression; Chitin; Induction; $N$-acetylglucoseamine; Regulation
\end{abstract}

\section{Background}

Chitin $\left(\mathrm{C}_{8} \mathrm{H}_{13} \mathrm{O}_{5} \mathrm{~N}\right)_{n}$ is the second most abundant natural polysaccharide composed of $N$-acetyl-D-glucosamine (GlcNAc) monomers. Chitin is found in many species including outer skeleton of crustaceans, insects, and as a component of fungi and algae cell walls (1-4). Chitinases (EC.3.2.1.14) are hydrolases able to degrade chitin into GlcNAc. There are endoand exo-chitinases that degrade chitin as a substrate (2). Different organisms including bacteria, protozoa, fungi, and plants produce chitinases $(1,5,6)$. These enzymes have several biological roles in different organisms. For instance, these enzymes are produced to provide carbon and nitrogen sources in bacteria (2, $3,5,6)$.
Generally, heterotrophic bacteria utilize glucose as a preferred carbon source. Meanwhile, in the presence of glucose, transcription of many genes that use other carbon sources are repressed in a mechanism called carbon catabolite repression (CCR) $(7,8)$. Most of reported chitinase encoding genes are also regulated by CCR. In Streptomyces plicatus, characterization of the promoter region of two chitinase genes, namely chi63 and chi35, showed their induction by chitin and repression in the presence of glucose $(9,10)$. Several other chitinase genes including chiA and chiC of Streptomyces lividans and chiA, chiB, chiC, chiD and chiF of Streptomyces coelicolor A3 (5) are similarly regulated by chitin and glucose. In Bacillus subtilis, most of the genes or operons that are under the control 
of CCR have a cis-acting catabolite responsive element (cre) $(7,11-14)$. This cre site (WTGNAANCGNWNNCW) located within, upstream or downstream of a promoter region and interact with a trans-acting complex, carbon catabolite protein $\mathrm{A}(\mathrm{CcpA})$ and $\mathrm{HPr}$ (S46 P) complex. CcpA is a DNA binding protein that belongs to LacI/GalR transcriptional regulators, which is able to repress or activate the transcription of genes depending on the location of cre site at the target promoter (11, 14-16). HPr is a histidine containing protein that forms a complex with CcpA, when it is phosphorylated at its serine residue number 46 (17).

B. pumilus strain SG2 is a halophilic and chitinolytic bacterium that produces two chitinases, ChiS and ChiL (18, 19). The expression of chiSL genes is induced by chitin as a sole carbon source, while it is repressed in the presence of glucose. In other words, $B$. pumilus SG2 chitinase encoding genes is controlled by carbon catabolite repression (CCR) (20). In the current study, activity of $\mathrm{P}_{\text {chis }}$ from B. pumilus SG2 was evaluated on a low copy plasmid in $B$. subtilis in order to investigate the possibility of construction of an expression system.

\section{Materials and Methods}

\subsection{Strains, Media and Growth Condition}

All strains are listed in (Table 1). The original genes and promoter are from B. pumilus SG2 strain which was isolated from high salt ecosystem, but cloning and experimental works were carried out in a standard $B$. subtilis called 3NA as explained in (Table 1). Escherichia coli JM109 was used for plasmid propagation. LB-agar supplemented with ampicillin (100 $\left.\mu \mathrm{g} . \mathrm{mL}^{-1}\right)$, chloramphenicol $\left(5 \mu \mathrm{g} . \mathrm{mL}^{-1}\right)$, or spectinomycin $\left(100 \mu \mathrm{g} . \mathrm{mL}^{-1}\right)$ were used for selection of $E$. coli and B. subtilis 3NA transformants. Minimal medium (MI) for transformation of B. subtilis was prepared by mixing $97.5 \mathrm{~mL}$ of Spizizen's minimal salts containing 2 g.L ${ }^{-1}\left(\mathrm{NH}_{4}\right)_{2} \mathrm{SO}_{4}, 14$ g.L. $\mathrm{K}_{2} \mathrm{HPO}_{4}, 6$ g.L $\mathrm{L}^{-1} \mathrm{KH}_{2} \mathrm{PO}_{4}$, 1 g.L $\mathrm{L}^{-1} \mathrm{Na}_{3} \mathrm{C}_{6} \mathrm{H}_{5} \mathrm{O}_{7} .2 \mathrm{H}_{2} \mathrm{O}, 0.2$ g.L $\mathrm{L}^{-1} \mathrm{MgSO}_{4} \cdot 7 \mathrm{H}_{2} \mathrm{O}, 5$ g. $\mathrm{L}^{-1}$ glucose, supplemented with $0.02 \%(\mathrm{w} / \mathrm{v})$

Table 1. Primers, plasmids and strains were used in this study

\begin{tabular}{|c|c|c|}
\hline Name & Description & Reference \\
\hline \multicolumn{3}{|l|}{ Oligonucleotides } \\
\hline ChiSLF10 & GGGCCCGGGTCATCAAGACGCAGATGTC & $(20)$ \\
\hline ChiSR1J & GGGGCATGCGAGCCCACTCTCTCTTTA & $(20)$ \\
\hline UP-CRE1 & TATGAAAACTAGAAATGTTGTTGTCTTCAGTGC & This study \\
\hline UP-CRE2 & GCACTGAAGACAACAACATTTCTAGTTTTCATATGC & This study \\
\hline s5767 & AAAGCTAGCTCATCAAGACGCAGATGTC & This study \\
\hline s5768 & AAACTTAAGCCССTTTTCATTAATTTTT & This study \\
\hline \multicolumn{3}{|l|}{ Plasmids } \\
\hline pDHAFB & bla, amyE::[cat, lacl, $\left.\mathrm{P}_{\text {spac }}\right]$ & $(22)$ \\
\hline pSUN279.2 & ori $_{\mathrm{pBS} 72}$, ori $i_{\mathrm{pUC} 18}$, ter- $\mathrm{P}_{\text {manR }}-\operatorname{manR}-\mathrm{P}_{\operatorname{man} P^{-l a c Z}, \mathrm{spcR}}$ & $(36)$ \\
\hline pUP-Chi2 & bla, amyE::[P chis $\left.^{-c h i S, ~ c a t ~}\right]$ & $(20)$ \\
\hline pUP-Chi2 $\Delta$ cresig & bla, amyE:: $\left[\mathrm{P}_{\text {chiS }} \Delta\right.$ cresig-chiS, cat $]$ & $(20)$ \\
\hline pUP-Chi2 $\Delta$ cre & bla, amyE::[P $\mathrm{P}_{\text {chiS } \Delta \text { cre }}$-chiS, cat $]$ & This study \\
\hline pChi1 & ori $_{\mathrm{pBS} 72}$, ori $_{\mathrm{puC18}}$, ter- $\mathrm{P}_{\text {chis- }}$ lacZ, spcR & This study \\
\hline pChi2 & ori $_{\mathrm{pBS} 72}$, ori $_{\mathrm{pUC18}}$, ter- $\mathrm{P}_{\text {chiS } \Delta c r e^{-l a c Z}, \mathrm{spcR}}$ & This study \\
\hline pChi3 & ori $_{\mathrm{pBS} 72}$, ori $i_{\mathrm{pUc} 18}$, ter- $\mathrm{P}_{\text {chiS } \Delta \text { cresig-lacZ, spcR }}$ & This study \\
\hline \multicolumn{3}{|l|}{ Strains } \\
\hline \multicolumn{3}{|l|}{ E. coli } \\
\hline JM109 & $\begin{array}{c}\operatorname{recA} 1, \text { endA1, gyrA96, thi-1, hsdR17 }\left(\mathrm{r}_{\mathrm{K}^{-}}, \mathrm{m}_{\mathrm{k}}^{+}\right), \text {mcrA, } \\
\text { supE44, gyrA96, relA1, } \lambda^{-}, \Delta\left(\text { lac-proAB), } \mathrm{F}^{\prime}(\operatorname{tra} D 36,\right. \\
\text { proAB+, lac/q, }(\Delta / a c Z) \mathrm{M} 15)\end{array}$ & (37) \\
\hline \multicolumn{3}{|l|}{ B. subtilis } \\
\hline 3NA & spo0A3 & (38) \\
\hline Chi7 & spo0A3 amyE::[$\left[\mathrm{P}_{\text {chiS } \Delta \text { cresig }}{ }^{-c h i S,}\right.$ cat $]$ & pUP-Chi2 $\Delta$ cresig $\rightarrow 3$ NA pChi 1 \\
\hline Chi8 & spo0A3 amyE::[$\left[\mathrm{P}_{\text {chiS } \Delta \text { cresig-chiS, cat }]}\right.$ & pUP-Chi2 $\Delta$ cresig $\rightarrow 3$ NA pChi2 \\
\hline Chi9 & spo0A3 amyE::[$\left[\mathrm{P}_{\text {chiS } \Delta \text { cresig-chiS, cat }]}\right.$ & pUP-Chi2 $\Delta$ cresig $\rightarrow 3$ NA pChi3 \\
\hline
\end{tabular}


casamino acids, and $5 \mathrm{mM} \mathrm{MgSO}_{4}$ (21).

Induction of strain $3 \mathrm{NA}$ containing pChi1, pChi2 or pChi3 was carried out using LB medium. LB medium $(85 \mathrm{~mL})$ in a $500 \mathrm{~mL}$ Erlenmeyer flask was inoculated by $1.7 \mathrm{~mL}$ of the overnight culture and incubated at $37^{\circ} \mathrm{C}$ with $200 \mathrm{rpm}$ shake. Cells were grown to an optical density of 0.4 at $600 \mathrm{~nm}$. Aliquots of $8 \mathrm{~mL}$ were divided in $100 \mathrm{~mL}$ Erlenmeyer flasks and induced with $0.2 \%(\mathrm{w} / \mathrm{v})$ inducers, i.e. chitin, chitin+glucose, $\mathrm{N}$ acetylglucosamine (GlcNAc), GlcNAc+glucose or without any inducer as the negative control. Colloidal chitin was prepared as described (18). Samples were collected $1 \mathrm{~h}$ after the addition of carbohydrates.

Minimal medium (96.5 mL of MI medium (without glucose) $+0.02 \% \mathrm{v} / \mathrm{v}$ glycerol) was used to study the $\beta$-galactosidase activity of prepared strains, namely 3NA pChi1, 3NA pChi2, 3NA pChi3, Chi7, Chi8 and Chi9. The inducers were $0.2 \%(\mathrm{w} / \mathrm{v})$ chitin $+0.2 \%$ $\mathrm{v} / \mathrm{v}$ glycerol, $0.2 \%(\mathrm{w} / \mathrm{v})$ chitin $+0.2 \%(\mathrm{w} / \mathrm{v})$ glucose, $0.2 \%(\mathrm{w} / \mathrm{v})$ glucose, and $0.2 \%(\mathrm{v} / \mathrm{v})$ glycerol. Sample collection was performed at $2 \mathrm{~h}$ intervals until $11 \mathrm{~h}$ after the induction. All experiments were performed three times and mean values were used for comparison.

\subsection{Construction of Expression Plasmids and Strains}

Plasmids and oligonucleotide primers are listed in (Table 1). Construction of pUP-Chi $2 \Delta$ cre was carried out using overlapping PCR to fuse the chitinases promoter to the coding region of $\beta$-galactosidase gene. $\mathrm{PCR}_{1}$ was performed using ChiSLF10 and UP-CRE2 primer pairs and plasmid pUPChi2 as a template. $\mathrm{PCR}_{2}$ was performed using primers (ChiSR1J and UPCRE1) and plasmid pUPChi2 as a template. $\mathrm{PCR}_{3}$ was performed using primers (ChiSLF10 and ChiSR1J) and $20 \mathrm{ng}$ of each $\mathrm{PCR}_{1}$ and $\mathrm{PCR}_{2}$ amplicons as templates. The final PCR product was inserted into pDHAFB via $C f r 9 I$ and $S p h$ I restriction sites. The final cassette was integrated into the amyE locus of $B$. subtilis chromosome to have a constitutive expression of chitinase. Using this method, the $\alpha$-amylase encoding gene was inactivated and the transformants were selected based on their chloramphenicol resistance (22). In order to create pChi1, pChi2 and pChi3 constructions, promoter of chitinase gene of B. pumilus SG2 was amplified in a PCR using s5767 and s5768 oligonucleotides and pUP-Chi2, pUP-Chi $2 \Delta \mathrm{cre}$, and pUP-Chi $2 \Delta$ cresig as the templates. The amplified fragment was inserted into a derivative of the theta replicating pBS72 plasmid (pSUN279.2), which is a low copy number plasmid in $B$. subtilis, upstream of the $l a c Z$ as the reporter gene using NheI (NEB) and AflII (NEB) restriction enzymes (Figure 1). The pSUN279.2 has also a pUC18 origin of replication for plasmid propagation in E. coli.

To integrate the $\mathrm{P}_{\text {chiSAcresig-chiS cassette into the }}$ chromosome of $B$. subtilis 3NA, plasmid pUPChi $2 \Delta$ cresig was used containing an amyE integration cassette. In this way, strain 3NA containing pChil, pChi2 or pChi3 was transformed to create Chi7, Chi8, and Chi9, respectively.
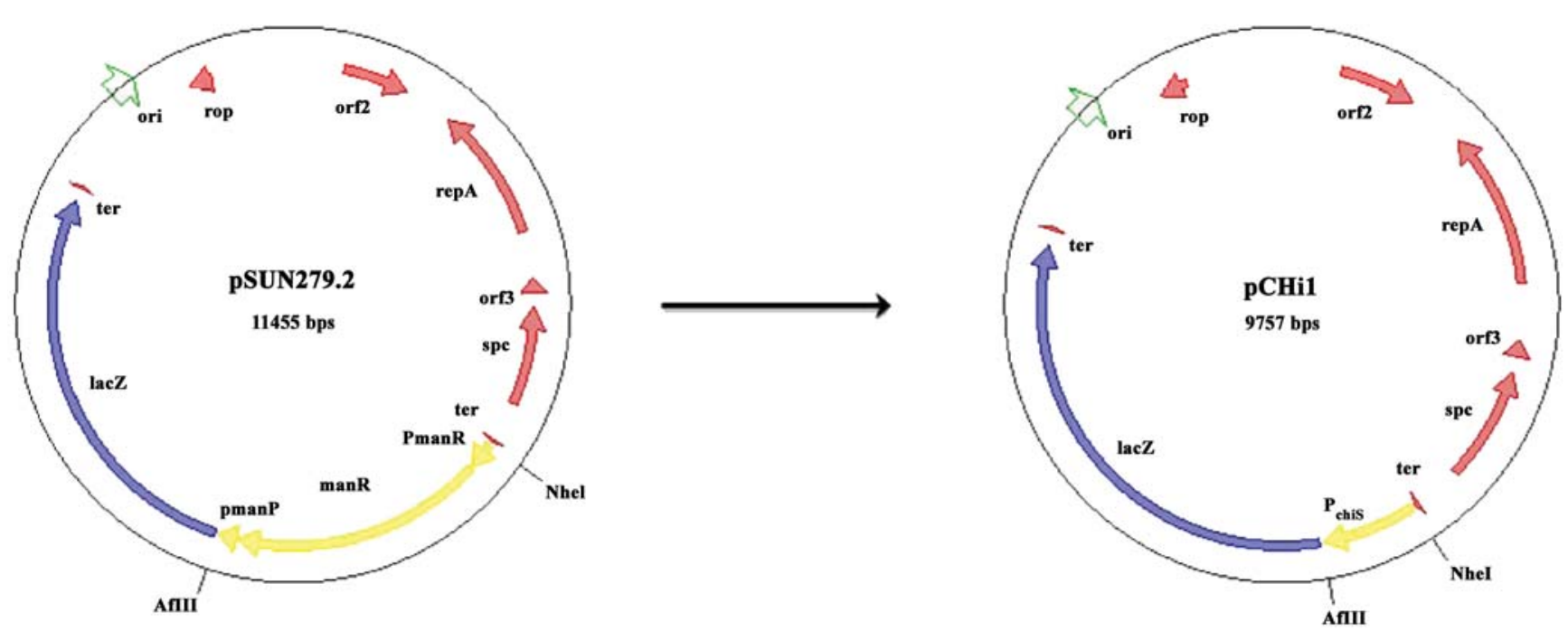

Figure 1. The plasmid maps of pSUN279.2 used as the parental vector and its derivative pChi1. The $\mathrm{P}_{\text {chis }}$ DNA sequence was inserted into pSUN279.1 via NheI and $A f l \mathrm{II}$ restriction sites 


\subsection{Enzyme Activity}

Production of $\alpha$-amylase was detected by the addition of iodine solution $(0.5 \%$ iodine in $1 \%$ potassium iodide solution) in nutrient agar containing $1 \%(\mathrm{w} / \mathrm{v})$ starch (23), while production of chitinase was detected using MI agar plates containing $0.5 \%(\mathrm{w} / \mathrm{v})$ chitin and $0.001 \%(\mathrm{v} / \mathrm{v})$ Congo Red (24). $\beta$-galactosidase activity was measured y using $o$-nitrophenyl-D-galactopyranoside (ONPG) as substrate according to Miller assay (25) and the result was given as Miller unit (MU). Ttest statistical analysis was used to demonstrate the significance and reliability of the quantitative results.

\section{Results}

\subsection{Activity of the Chitinase Promoter on a pBS72 Derivative in B. subtilis}

Regulation of $\mathrm{P}_{\text {chiS }}$ and its derivative $\mathrm{P}_{\text {chis } \Delta \text { cresig }}$ has been already investigated in $B$. subtilis using an integrated $\mathrm{P}_{\text {chis }}$ lac $Z$ cassette (20). To develop a new gene expression system for $B$. subtilis, $\mathrm{P}_{\text {chis }}$ was inserted upstream of $l a c Z$, as a reporter gene, on pSUN279. Plasmid pSUN279 is an E. coli (ori $\left.i_{\mathrm{pUC18}}\right)$ - $B$. subtilis (ori $i_{\mathrm{pBS} 72}$ ) stable low copy number shuttle vector in $B$. subtilis. Transformation of $B$. subtilis 3NA with pChil $\left(\mathrm{P}_{c h i S}\right)$ was followed by induction of the transformed mutants in LB in the presence of chitin or GlcNAc with (out) glucose. Measurement of the $\beta$-galactosidase activity of the 3NA pChil strain showed low

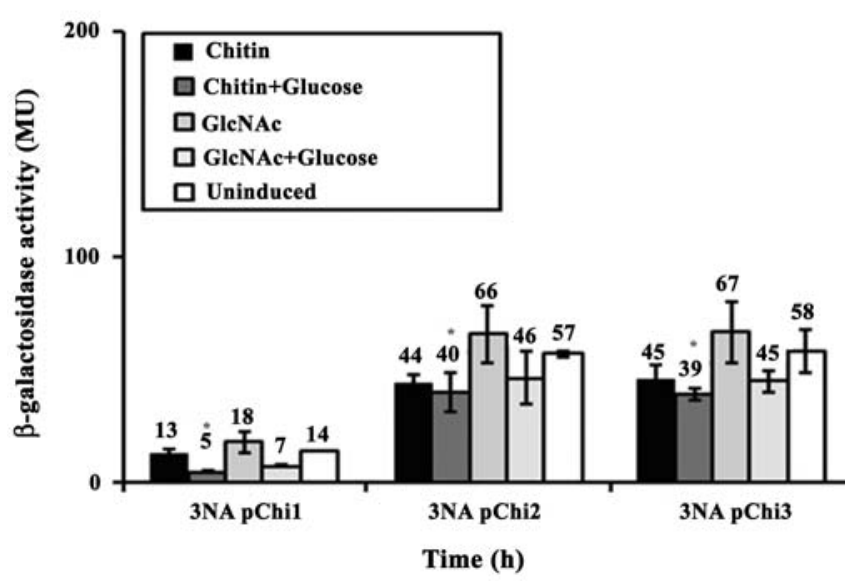

Figure 2. $\beta$-galactosidase activity of the $B$. subtilis strains 3NA pChil (A), 3NA pChi2 (B) and 3NA pChi3 (C) in LB medium with chitin $(0.2 \%)$ or GlcNAc $(0.2 \%)$ alone or together with glucose $(0.2 \%)$. As the control, no additional carbohydrate was added to the medium (uninduced). The $\beta$ galactosidase measurements were carried out $1 \mathrm{~h}$ after the addition of carbohydrates. The experiment was performed three times and mean values and standard deviations (error bar) are shown amount of the $\beta$-galactosidase activity up to $18 \mathrm{MU}$ after $1 \mathrm{~h}$ of induction in LB. Since there was not a significant difference in the $\beta$-galactosidase activity with chitin or GlcNAc as an inducer compared to the uninduced culture, it was concluded that the expression from the $\mathrm{P}_{c h i s}$ promoter was constitutive (Figure 2). In contrast, the addition of glucose reduced $\beta$-galactosidase activity of 3NA pChi1 by 2.6 - and 2.5 -fold in the presence of chitin and GlcNAc, respectively (Figure $2)$. In order to investigate the effect of the cre site on the activity of $\mathrm{P}_{c h i S}$, two shortened versions of $\mathrm{P}_{c h i S}$, namely $\mathrm{P}_{\text {chis } \Delta \text { cre }}$ and $\mathrm{P}_{\text {chis } \Delta \text { cresig }}$, were inserted upstream of lacZ. The $\mathrm{P}_{\text {chis } \Delta \text { cre }}$ lacked only the cre site, whereas $\mathrm{P}_{\text {chiS } \Delta \text { cresig }}$ had an additional deletion upstream of the cre site (for the exact promoter sequence see Heravi, Shali (20)). Like 3NA pChil, the $\beta$-galactosidase activities of strains 3NA pChi2 $\left(\mathrm{P}_{\text {chiS } \Delta \text { cre }}\right)$ and 3NA pChi3 ( $\left.\mathrm{P}_{\text {chiS } \Delta \text { cresig }}\right)$ were measured. The results revealed that the deletion of the cre site increased the activity in all culture conditions (Figure 2). Unlike 3NA pChi1, in both 3NA pChi2 and 3NA pChi3, $\mathrm{P}_{\text {chis }}$ was constitutive. As expected, glucose had no effect on the production of $\beta$-galactosidase and the level of enzyme was significantly increased up to $67 \mathrm{MU}$ in 3NA pChi2 and 3NA pChi3. Likewise, no drastic difference was observed between the $\beta$-galactosidase activity of 3NA pChi2 and 3NA pChi3 (Figure 2). Altogether, the results indicated that $\mathrm{P}_{\text {chis } \Delta \text { cre }}$ and $\mathrm{P}_{\text {chiS } \Delta \text { cresig }}$ had higher activities than $\mathrm{P}_{\text {chis }}$. In between, only $\mathrm{P}_{c h i S}$ was regulated by glucose.

\subsection{Strain and Media Optimization for the Activity of $P_{\text {chis }}$ and its Derivatives}

Since the $\beta$-galactosidase activities of strains 3NA pChi1, 3NA pChi2 and 3NA pChi3 were too low in LB, MI medium containing glycerol was used with the addition of different carbohydrates (glycerol, glucose and chitin). The $\beta$-galactosidase activity of each strain was measured with $2 \mathrm{~h}$ intervals up to $11 \mathrm{~h}$ (Figure 3 A-C). Comparing to LB medium, the results indicated an increase in $\beta$-galactosidase activity. Moreover, the $\beta$-galactosidase activity of each construct was similar in different conditions, showing that the $\mathrm{P}_{c h i s}$ and its derivatives were constitutive in minimal medium with the defined composition. The higher $\beta$-galactosidase activities were obtained for 3NA pChi2 and 3NA pChi3 after $11 \mathrm{~h}$ of induction with about $800-1,100$ MU.

Plasmid pUP-Chi2 $\Delta$ cresig with the $\mathrm{P}_{\text {chis } \Delta \text { cresig-chiS }}$ cassette was integrated into the genome of strain 3NA pChi1, 3NA pChi2 and 3NA pChi3 at amyE locus. The 

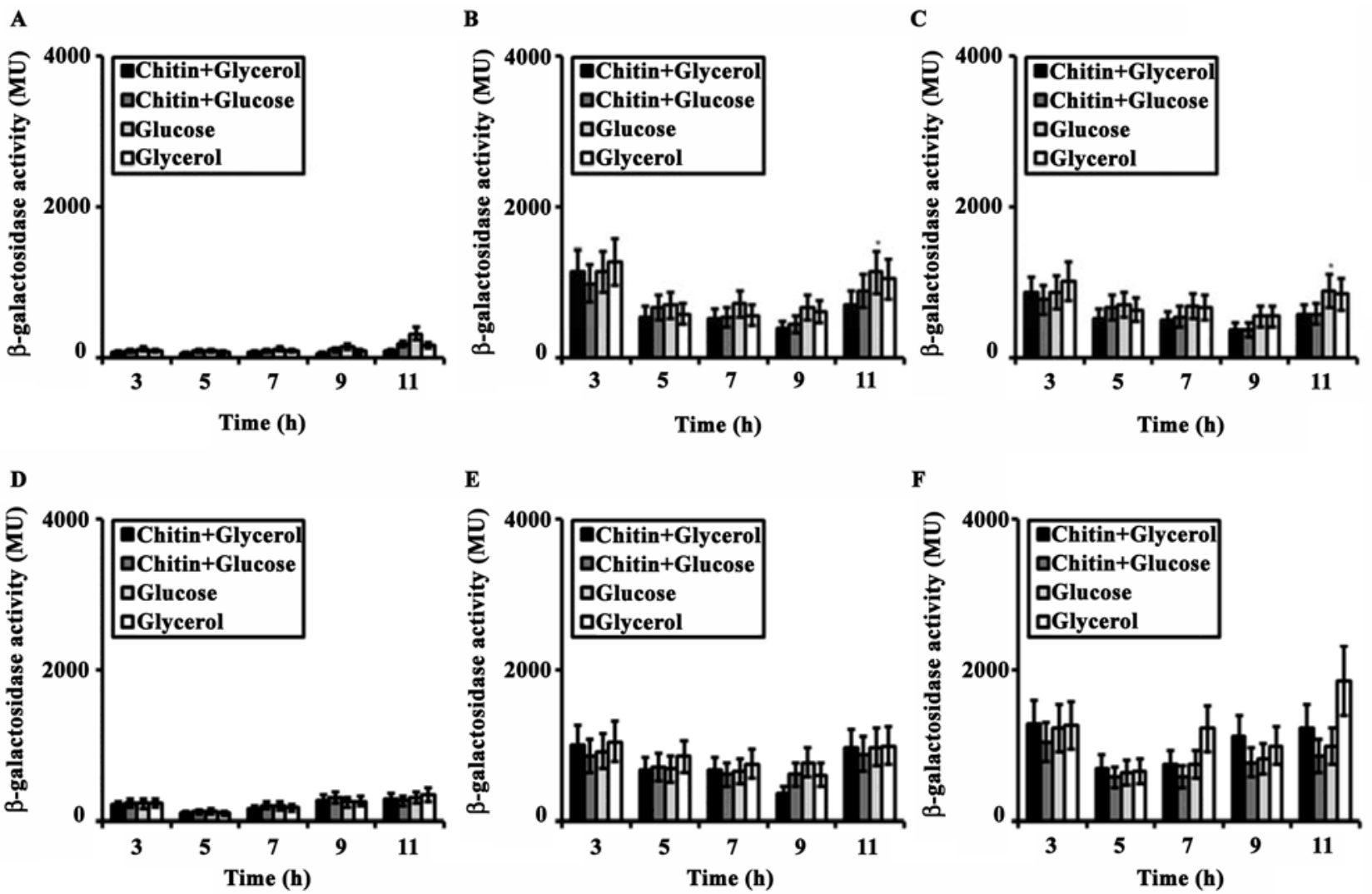

Figure 3. $\beta$-galactosidase activity of the strains A: 3NA pChi1, B: 3NA pChi2, C: 3NA pChi3, D: Chi7, E: Chi8 and F: Chi9 in the minimal MI medium containing $0.02 \%$ glycerol. Different carbohydrates, i.e. chitin, glucose and glycerol $(0.2 \%)$, were added to the culture media. $\beta$-galactosidase activity was measured $3,5,7,9$ and $11 \mathrm{~h}$ after induction. All the experiments were performed three times and mean values and standard deviations (error bar) are shown

newly constructed strains Chi7, Chi8 and Chi9 were able to degrade chitin and use it as carbon source. The integration of $\mathrm{P}_{\text {chiS } \Delta \text { cresig }}$-chiS into the amyE gene was confirmed using starch agar (Figure 4 A-F). As a result, strains 3NA pChi1, 3NA pChi2 and 3NA pChi3 showed a halo around their colonies resulted by starch degradation (negative controls; Figure 4 A-C), whereas strains Chi7, Chi8 and Chi9 showed no amylase activity and therefore, they showed no halo around the colonies (Figure 4 D-F). Likewise, expression of chitinase was confirmed using chitinase-Congo Red agar. The production of clear halos around the colonies of
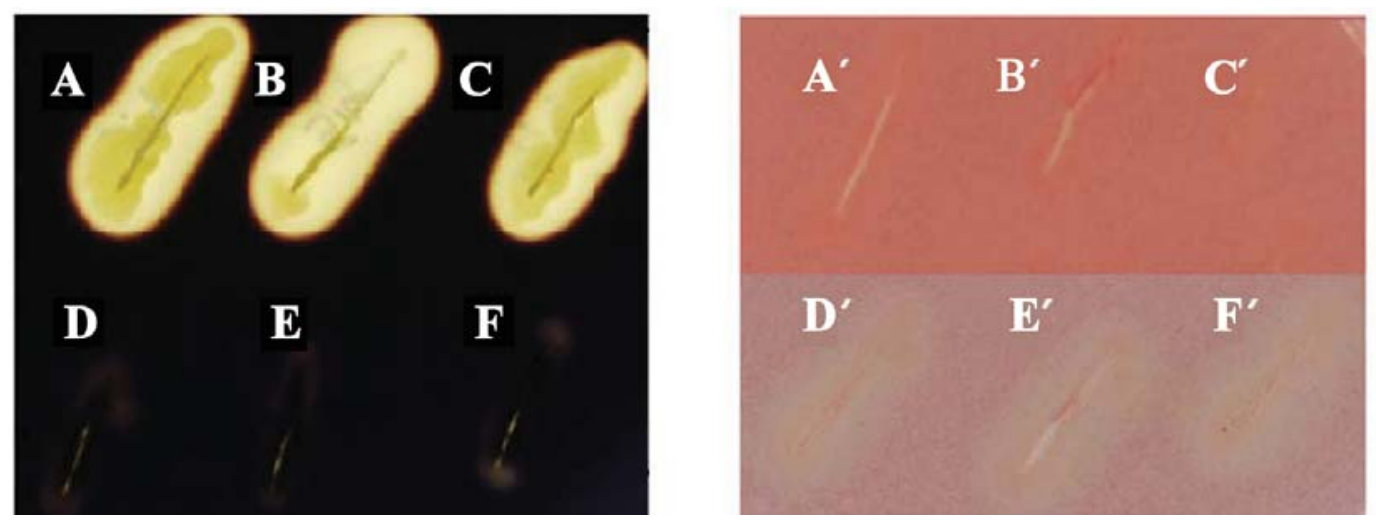

Figure 4. Production of $\alpha$-amylase was detected on the starch agar (A-F), while chitinase production was tested on the chitin-Congo Red agar $\left(\mathrm{A}^{\prime}-\mathrm{F}^{\prime}\right)$. Strains 3NA pChi1 (A), 3NA pChi2 (B), 3NA pChi3 (C), Chi7 (D), Chi8 (E) and Chi9 (F) were streaked on the agar plates. Production of clear halos around the colonies was tested after $48 \mathrm{~h}$ of incubation at $37^{\circ} \mathrm{C}$. 
Chi7, Chi8 and Chi9 showed the chitinase activity compared to strains 3NA pChi1, 3NA pChi2 and 3NA pChi3 (Figure $4 \mathrm{~A}^{\prime}-\mathrm{F}^{\prime}$ ).

Given that chitinase breaks the chitin branches increasing the amount of GlcNAc as carbon source, the activity of $\mathrm{P}$ chis in strain Chi7 with the addition of different carbohydrates was investigated with $2 \mathrm{~h}$ interval up to $11 \mathrm{~h}$ (Figure 3D). Strain Chi7 showed identical activity with different carbon sources similar to 3NA pChil. Overall, the $\beta$-galactosidase activity of Chi7 was 2- to 3-fold higher than 3NA pChi1. Additionally, the activities of $\mathrm{P}_{\text {chiS } \Delta c r e}$ and $\mathrm{P}_{\text {chiS } \Delta \text { cresig }}$ from strains Chi8 and Chi9 in the same growth condition were measured. The $\beta$-galactosidase activities of both Chi8 and Chi9 in different carbohydrate sources were similar and greater than Chi7 (Figure 3D-4F). Comparison of Chi8 and Chi9 with their parental strains 3NA pChi2 and 3NA indicated that the integration of chiS enhanced the $\beta$-galactosidase activity in Chi9 (Figure $3 \mathrm{~B}-\mathrm{F}$ ). Furthermore, the $\beta$-galactosidase activity of Chi9 was slightly increased in the presence of glycerol and chitin glycerol compared to chitin with (out) glucose reaching up to $1,800 \mathrm{MU}$ (Figure 3F). Overall, the $\beta$-galactosidase activity was significantly increased by changing the medium to a defined medium. Moreover, the $\mathrm{P}_{\text {chis }}$ and its derivatives showed constitutive activity in the minimal medium.

\section{Discussion}

Since chitin is an abundant polysaccharide in nature, it can be used as a cheap carbon source in growth media. Nevertheless, the genome of B. subtilis 3NA which was used to analyse the promoter in this study, contains no chitinase encoding gene to secret into the surrounding environment and sense the chitin and degrade it, the chitinase gene of B. pumilus SG2 plus its upstream promoter was inserted into the genome of this standard B. subtilis. promoter. Therefore, Chitinase encoding genes of $B$. pumilus SG2 are expressed by two promoters with a cre site in between. The activity of this promoter region is inducible by chitin and repressible by glucose in B. pumilus SG2, while the promoter activity is only repressible by glucose in B. subtilis (20). In the present study, the activity of chitinase promoter was investigated on a low copy plasmid using lac $Z$ (encodes $\beta$-galactosidase), as a reporter gene. In addition to the wild type $\mathrm{P}_{\text {chis }}$, two deletions were carried out in the cis-regulatory element of the $\mathrm{P}_{\text {chis }}$ to test the possible effect of these deletions on the promoter activity.

Firstly, LB medium was used as the basal medium, which resulted in a weak activity of the wild type promoter in B. subtilis (max. $18 \mathrm{MU}$ ). Deletion of the cre site and its flanking region increased the activity slightly although the level of lacZ expression was low and constitutive (approx. $70 \mathrm{MU}$ ). This could be due to the shortened untranslated region of the lacZ mRNA on pChi2 and pChi3. Similarly, shortening of the untranslated region of lac $Z$ mRNA expressed by $\mathrm{P}_{m t l A}$ increased the $\beta$-galactosidase activity in the $B$. subtilis host strain (26). Replacing the LB medium with M9 medium led to weak growth of the strains (data not shown). Hence, MI minimal medium containing casamino acids was utilized as the basal media for the chitinases producing strains. In the latter medium, stronger activity of the chitinase promoter was observed. Comparison of the different growth conditions with the negative control showed that the activities of these promoters neither can be regulated nor was strong in B. subtilis. Besides, catabolite repression was not observed in the presence of glucose in minimal medium. Integration of the chitinase had increased the $\beta$-galactosidase activity in the presence of chitin and chitin + glucose in strain Chi7 compared with Chil as well as Chi3 compared with Chi9. B. subtilis contains no chitin degradation system $(27,28)$; however, it has only an $\mathrm{N}$-acetylglucosamine utilization system (29). Therefore, the over-produced chitinase could provide further $N$-acetylglucosamine for the growth of the cells. Nevertheless, the increase of the $\beta$-galactosidase activity in the absence of chitin remains unclear. In current study, $B$. subtilis selected as a host organism for recombinant protein expression. B. subtilis has significant potential for production of industrial enzyme including proteases, $\alpha$-amylase and lipases (30). Using $B$. subtilis as an expression system has several advantages. The genome of this species has been sequenced. In addition, $B$. subtilis classified as a GRAS organism and without production of any harmful exotoxins or endotoxins. In addition, it could naturally secret recombinant proteins into the extracellular medium, which facilitate purification stage. Despite these benefits, using B. subtilis has several drawbacks including lack of suitable expression vectors (31-33). Until now several expression systems have been developed in $B$. subtilis. Among these expression systems are the starch-inducible amylase promoter, xylose-inducible xylA promoter, $\mathrm{P}_{g l v}$ promoter, prophage-derived heatinducible gene expression systems and $B$. subtilis expression system involving the mannose operon (34). In addition $E$. coli lac repressor-based expression system has been developed for B. subtilis that could pro- 
duce very high levels of recombinant proteins after induction using IPTG $(30,34,35)$.

The chitinase promoter developed in this study, has potential to be used in an expression vector that could be induced by chitin. In addition, compared to the other inducers like IPTG and lactose, chitin is definitely cheaper and more available as an inducer.

\section{Acknowledgements}

Authors would like to thank Dr. J. Altenbuchner (Institut für Industrielle Genetik, Universität Stuttgart) for his suggestions throughout the study. Funding for the project was provided by the Iran National Science Foundation (Project no. 90004656).

\section{References}

1. Tsujibo H, Kubota T, Yamamoto M, Miyamoto K, Inamori Y. Characterization of chitinase genes from an alkaliphilic actinomycete, Nocardiopsis prasina OPC-131. Appl Environ Microbiol. 2003;69(2):894-900. DOI: 10.1128/AEM.69.2. 894-900.2003

2. Swiontek M, Brzezinska WD. Occurrence and Activity of the Chitinolytic Bacteria of Aeromonas Genus. Pol J Environ Stud. 2001;10(1):27-31.

3. Nisa Rachmania Mubarik IM. Chitinolytic Bacteria Isolated from Chili Rhizosphere: Chitinase Characterization and Its Application as Biocontrol for Whitefly (Bemisia tabaci Genn.). Am J Agr Biol Sci. 2010;5(4):430-435. DOI: 10.3844/ ajabssp.2010. 430.435

4. Li H, Greene LH. Sequence and structural analysis of the chitinase insertion domain reveals two conserved motifs involved in chitin-binding. PLOS One. 2010;5(1):0008654. DOI: 10.1371/journal.pone.0008654

5. Patil RS, Ghormade VV, Deshpande MV. Chitinolytic enzymes: an exploration. Enzyme Microb Technol. 2000;26(7):473-483. DOI:10.1016/S0141-0229(00)00134-4

6. Zhu XF, Zhou Y, Feng JL. Analysis of both chitinase and chitosanase produced by Sphingomonas sp. CJ-5. J Zhejiang Univ Sci B. 2007;8(11):831-838. DOI: 10.1631/jzus.2007. B0831

7. Singh KD, Schmalisch MH, Stulke J, Gorke B. Carbon catabolite repression in Bacillus subtilis: quantitative analysis of repression exerted by different carbon sources. J Bacteriol. 2008;190(21):7275-7284. DOI:10.1128/JB.00848-08

8. Luesink EJ, van Herpen RE, Grossiord BP, Kuipers OP, de Vos WM. Transcriptional activation of the glycolytic las operon and catabolite repression of the gal operon in Lactococcus lactis are mediated by the catabolite control protein CcpA. Mol Microbiol. 1998;30(4):789-798.

9. Delic I, Robbins P, Westpheling J. Direct repeat sequences are implicated in the regulation of two Streptomyces chitinase promoters that are subject to carbon catabolite control. Proc Natl Acad Sci USA. 1992;89(5):1885-1889. DOI: 10.1073/ pnas.89.5.1885

10. Fujii T, Miyashita K, Ohtomo R, Saito A. DNA-binding protein involved in the regulation of chitinase production in
Streptomyces lividans. Biosci Biotechnol Biochem. 2005;69(4):790-799. DOI: 10.1271/bbb.69.790

11. Kim JH, Yang YK, Chambliss GH. Evidence that Bacillus catabolite control protein CcpA interacts with RNA polymerase to inhibit transcription. Mol Microbiol. 2005;56(1):155-162. DOI: 10.1111/j.1365-2958.2005.04496.x

12. Deutscher J, Francke C, Postma PW. How phosphotransferase system-related protein phosphorylation regulates carbohydrate metabolism in bacteria. Microbiol Mol Biol Rev. 2006;70(4):939-1031. DOI: 10.1128/MMBR.00024-06

13. Fujita Y. Carbon catabolite control of the metabolic network in Bacillus subtilis. Biosci Biotechnol Biochem. 2009;73(2):245-259. DOI: 10.1271/bbb.80479

14. Hueck CJ, Hillen W. Catabolite repression in Bacillus subtilis: a global regulatory mechanism for the gram-positive bacteria? Mol Microbiol. 1995;15(3):395-401. DOI: 10.1111/j.13652958.1995.tb02252.x

15. Zalieckas JM, Wray LV, Jr., Fisher SH. Expression of the Bacillus subtilis acsA gene: position and sequence context affect cre-mediated carbon catabolite repression. J Bacteriol. 1998;180(24):6649-6654.

16. Henkin TM. The role of CcpA transcriptional regulator in carbon metabolism in Bacillus subtilis. FEMS Microbiol Lett. 1996;135(1):9-15. DOI: 10.1111/j.1574-6968.1996.tb07959.x

17. Deutscher J, Reizer J, Fischer C, Galinier A, Saier MH, Jr., Steinmetz M. Loss of protein kinase-catalyzed phosphorylation of HPr, a phosphocarrier protein of the phosphotransferase system, by mutation of the $p t s H$ gene confers catabolite repression resistance to several catabolic genes of Bacillus subtilis. J Bacteriol. 1994;176(11):3336-3344.

18. Ahmadian G, Degrassi G, Venturi V, Zeigler DR, Soudi M, Zanguinejad P. Bacillus pumilus SG2 isolated from saline conditions produces and secretes two chitinases. $J$ Appl Microbiol. 2007;103(4):1081-1089. DOI: 10.1111/j.13652672.2007.03340.x

19. Vahed M, Motalebi E, Rigi G, Akbari Noghabi K, Soudi MR, Sadeghi M, Ahmadian G. Improving the Chitinolytic Activity of Bacillus pumilus SG2 by Random Mutagenesis. $J$ Microbiol Biotechnol. 2013;23(11):1519-1528. DOI: 10.4014/jmb. 1301.01048

20. Heravi KM, Shali A, Naghibzadeh N, Ahmadian G. Characterization of cis-acting elements residing in the chitinase promoter of Bacillus pumilus SG2. World J Microbiol Biotechnol. 2013:1-9. DOI : 10.1007s11274-013-1569-9

21. Harwood C. R. CSM. Plasmids. in Molecular biological methods for Bacillus: John Wiley and Sons, Chichester, England; 1990. p.57-144.

22. Yamamoto H, Mori M, Sekiguchi J. Transcription of genes near the sspE locus of the Bacillus subtilis genome. Microbiology (Reading, England). 1999;145(Pt8):2171-2180. DOI: $10.1099 / 13500872-145-8-2171$

23. Fuwa H. A new method for microdetermination of amylase activity by the use of amylose as the substrate. $J$ Biochem. 1954;41(5):583-603.

24. Teather RM, Wood PJ. Use of Congo red-polysaccharide interactions in enumeration and characterization of cellulolytic bacteria from the bovine rumen. Appl Environ Microbiol. 1982;43(4):777-780. 
25. Miller JH. Experiments in Molecular Genetics: Cold Spring Harbor Laboratory Press; 1972. p. 982.

26. Heravi KM, Wenzel M, Altenbuchner J. Regulation of $m t l$ operon promoter of Bacillus subtilis: Requirements of its use in expression vectors. Microb Cell Fact. 2011;10. DOI: 10.1186/1475-2859-10-83

27. Kunst F, Ogasawara N, Moszer I, Albertini AM, Alloni G, Azevedo V, et al. The complete genome sequence of the Gram-positive bacterium Bacillus subtilis. Nature 1997;390(6657):249-256.

28. Barbe V, Cruveiller S, Kunst F, Lenoble P, Meurice G, Sekowska A, Vallenet D, Wang T, Moszer I, Médigue C, Danchin A. From a consortium sequence to a unified sequence: the Bacillus subtilis 168 reference genome a decade later. Microbiology (Reading, England). 2009;155(Pt 6):17581775. DOI: 10.1099/mic.0.027839-0

29. Reizer J, Bachem S, Reizer A, Arnaud M, Saier MH, Jr., Stülke J. Novel phosphotransferase system genes revealed by genome analysis - the complete complement of PTS proteins encoded within the genome of Bacillus subtilis. Microbiology (Reading, England). 1999;145(Pt12):3419-3429. DOI: 10. 1099/00221287145-12-3419

30. Bongers RS, Veening JW, Van Wieringen M, Kuipers OP, Kleerebezem M. Development and characterization of a subtilin-regulated expression system in Bacillus subtilis: strict control of gene expression by addition of subtilin. Appl Environ Microbiol. 2005;71(12):8818-8824. DOI: 10.1128/AEM.71.12.8818-8824.2 005

31. Demain AL, Vaishnav P. Production of recombinant proteins by microbes and higher organisms. Biotechnol Adv.
2009;27(3):297-306.DOI: 10.1016/j.biotechadv.2009.01.008

32. Lam KH, Chow KC, Wong WK. Construction of an efficient Bacillus subtilis system for extracellular production of heterologous proteins. J Biotechnol. 1998;63(3):167-177. DOI:10.1016/S0168-1656(98)00041-8

33. Westers L, Westers H, Quax WJ. Bacillus subtilis as cell factory for pharmaceutical proteins: a biotechnological approach to optimize the host organism. Biochim Biophys Acta. 2004;11:1-3. DOI: 10.1016/j.bbamcr.2004.02.011

34. Wenzel M, Muller A, Siemann-Herzberg M, Altenbuchner J. Self-inducible Bacillus subtilis expression system for reliable and inexpensive protein production by high-cell-density fermentation. Appl Environ Microbiol. 2011;77(18):6419-6425. DOI: 10.1128/AEM.05219-11

35. Ming YM, Wei ZW, Lin CY, Sheng GY. Development of a Bacillus subtilis expression system using the improved Pglv promoter. Microb Cell Fact. 2010;9(55):1475-2859. DOI:10.1186/1475-2859-9-55

36. Sun T, Altenbuchner J. Characterization of a mannose utilization system in Bacillus subtilis. J Bacteriol. 2010;192(8): 2128-2139. DOI: 10.1128/JB.01673-09

37. Yanisch-Perron C, Vieira J, Messing J. Improved M13 phage cloning vectors and host strains: nucleotide sequences of the M13mp18 and pUC19 vectors. Gene. 1985;33(1):103-119. DOI:10.1016/0378-1119(85)90120-9

38. Michel JF, Millet J. Physiological studies on early-blocked sporulation mutants of Bacillus subtilis. J Appl Bacteriol. 1970;33(1):220-227. DOI: 10.1111/j.1365-2672.1970.tb052 46.x 